\title{
СКОРОСТЬ ПОТЕРИ ВЛАГИ ЗЕРНОМ КУКУРУЗЫ В ПЕРИОД СОЗРЕВАНИЯ В ЗАВИСИМОСТИ ОТ ГЕНОТИПА И УСЛОВИЙ СРЕДЫ
}

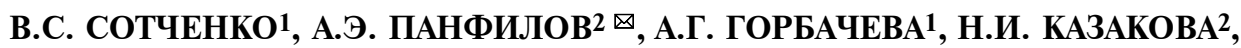 И.А. ВЕТОШКИНА ${ }^{1}$}

Высокая влажность зерна при уборке - один из факторов, сдерживающих расширение посевов кукурузы (Zea mays L.) в Уральском регионе. Снижение уборочной влажности семян достигается селекцией кукурузы на скороспелость (раннее цветение початка) и на ускоренную потерю влаги зерном в предуборочный период. В нашем исследовании впервые установлено, что в условиях юга России на фоне погодных условий, слабо лимитирующих процесс потери влаги зерном кукурузы, его уборочная влажность обусловлена скоростью влагоотдачи в предуборочный период, тогда как в Уральском регионе на периодически неблагоприятном фоне - главным образом скороспелостью изученных гибридов. Цель работы - выявление гибридов кукурузы с повышенной скоростью потери влаги в период созревания зерна и оценка проявления этого признака на неблагоприятном гидротермическом фоне. Исследования проводили в 2016-2018 годах в двух контрастных географических пунктах - в предгорной зоне Северного Кавказа (опытное поле Всероссийского НИИ кукурузы, п. Пятигорский, Предгорный р-н, Ставропольский край) и в северной лесостепи Южного Урала (Южно-Уральский ГАУ, с. Миасское, Красноармейский р-н, Челябинская обл.) - на шести ультраранних гибридах кукурузы (Zea mays L.) Нур, Росс 130 МВ, Обский 140 CВ, Кубанский 141 СВ, Машук 150 МВ, Уральский 150 и раннеспелом Биляр 160. Полевой опыт был заложен в 3-кратной повторности методом организованных повторений с рандомизированным размещением вариантов. Регистрировали фазы всходов, цветения початка и физиологической спелости зерна, о наступлении которой судили по появлению темного слоя у основания зерна. Наблюдения за влажностью зерна на Северном Кавказе проводили с 25 июля по 11 сентября, на Южном Урале - с 15 августа по 10 октября. Влажность зерна определяли гравиметрическим методом. Образцы массой не менее 70 г высушивали при температуре $150{ }^{\circ} \mathrm{C}$ (сушильный шкаф SNOL 58/350, «Elektrotechnika, AB», Литовская Республика) до постоянной массы (ее определяли с использованием электронных весов CAS MW-II, «CAS Corporation», Республика Корея). Для анализа отбирали и полностью обмолачивали средние образцы початков массой от 1,2 до 1,8 кг по 10 шт. в трех повторениях. Периодический отбор проб зерна проводили с интервалом в 3-7 сут, что обеспечивало от 8 до 16 контрольных точек. Проверку статистических гипотез осуществляли методами дисперсионного, корреляционного и регрессионного анализа. Установлено, что календарные сроки цветения початка в северном пункте исследований отмечаются на 22-36 сут позднее, чем на юге страны, и приходятся на начало или конец III декады июля. В условиях Северного Кавказа цветение наблюдалось в III декаде июня-начале июля, зерно достигало физиологической спелости в период с 1 по 7 августа, а процессы созревания и налива ультраранних гибридов проходили на благоприятном гидротермическом фоне. Следовательно, условия среды не ограничивали скорость потери влаги зерном, что обеспечило объективную оценку различий между гибридами по исследуемому признаку. Были выявлены существенные различия по скорости влагоотдачи как между пунктами исследований, так и между изученными гибридами. В Северо-Кавказском регионе скорость потери влаги зерном после достижения физиологической спелости колебалась по гибридам от 0,63 до 0,78 \%/сут при слабом варьировании по годам. В Уральском регионе на фоне высокой относительной влажности и низкой температуры воздуха в предуборочный период скорость влагоотдачи снижалась до 0,21-0,35 \%/сут, а в благоприятных гидротермических условиях достигала лишь 0,52-0,72 \%/сут. Установлено, что уборочная влажность зерна кукурузы связана с двумя основными признаками гибридов: скороспелостью и способностью к быстрой потере влаги на заключительных этапах онтогенеза. Вклад каждого из этих признаков определяется условиями созревания зерна: для юга России влажность зерна в значительной степени определяется способностью гибрида к ускоренной влагоотдаче, в условиях Южного Урала основное значение имеет раннее цветение початка. Различия между гибридами по скорости потери влаги в этих условиях проявляются нерегулярно и зачастую нивелируются влиянием среды. Следовательно, для северной зоны кукурузосеяния селекция кукурузы на способность к быстрой потере влаги зерном имеет смысл лишь в сочетании с отбором на короткий вегетационный период, который должен рассматриваться как приоритетный признак при создании адаптированных гибридов.

Ключевые слова: кукуруза, ультраранние гибриды, онтогенез, вегетационный период, влажность зерна, скорость влагоотдачи, Южный Урал, Северный Кавказ. 
Одна из тенденций развития кукурузосеяния в России заключается в расширении посевов этой культуры в северном направлении, в том числе в обширном и разнообразном по комплексу лимитирующих факторов Уральском регионе. Этот процесс сдерживает высокая влажность зерна при уборке. Наиболее жесткие ограничения по предельному уровню уборочной влажности (25-30 \%) возникают при заготовке зерна с термической сушкой, которое предназначено для длительного хранения (1). Эффективность производства альтернативных видов корма из кукурузы (консервированного влажного зерна и высокоэнергетического силоса) также зависит от содержания влаги в зерне вследствие тесной корреляции между этим параметром и остальными элементами химического состава зерновки, включая главный целевой компонент при выращивании культуры - крахмал (2-5).

Основной способ снижения влажности зерна в полевых условиях селекция кукурузы на скороспелость. В зависимости от зоны выращивания и назначения посевов (на силос или зерно) гибриды, адаптированные для Урала, должны характеризоваться числами от 110 до 170 ед. ФАО $(6,7)$. Создание гибридов с ранним цветением составляет значительную часть российских программ по селекции кукурузы (8). В мировой селекции это направление развивается локально, главным образом для заполнения северных экологических ниш (9-11). В большинстве зарубежных публикаций в качестве основных целей селекции кукурузы указаны высокая потенциальная продуктивность (12-15), устойчивость к засухе $(2,16-18)$, холодостойкость $(19,20)$. Отметим, что последний признак косвенно связан с проблемой снижения уборочной влажности зерна, поскольку обеспечивает стабильное развитие кукурузы в условиях пониженных температур.

При создании ультраранних образцов кукурузы может быть использован рекуррентный отбор на раннее цветение из промышленных или специально созданных для этой цели гибридов, а также из местных популяций с высоким генетическим разнообразием по различным признакам $(10,21$, 22). Особую ценность представляют изолированные популяции - доноры широкого комплекса хозяйственно полезных признаков (23). Сформированные под влиянием длительного искусственного и естественного отбора, они служат потенциальными источниками скороспелости (24).

Современное развитие селекции на скороспелость обеспечивает гарантированное достижение зерном кукурузы физиологической спелости практически до $56^{\circ}$ с.ш. Однако даже у ультраранних гибридов класса созревания ФАО 130-150, адаптированных для регионов с дефицитными ресурсами тепла, уборочная влажность зерна под влиянием гидротермических условий варьирует в широком диапазоне и приобретает значения, при которых термическое досушивание связано с необоснованно высокими издержками (25).

В качестве дополняющего или альтернативного направления, обеспечивающего регулирование влажности зерна в период созревания, рассматривается селекция кукурузы на ускоренную потерю влаги зерном (2629). Способность зерна кукурузы к быстрой влагоотдаче - полигенный признак, обусловленный комплексом морфологических и физиологических особенностей генотипа: типом эндосперма (зубовидный, кремнистый или промежуточный), размером зерна, плотностью оберточных листьев початка, высотой расположения початка над поверхностью почвы, толщиной стержня, толерантностью к субоптимальным температурам (29-32). Отмечена высокая вариация по скорости потери влаги как у промышленных гибридов, так и у самоопыленных линий - от 0,5 до 1,3\% в сутки (33-36).

Процесс снижения влажности зерна в предуборочный период про- 
текает в два этапа. До наступления физиологической спелости он обусловлен аккумуляцией органического вещества в эндосперме и зависит главным образом от температуры воздуха. После физиологической спелости влага теряется вследствие физического испарения, скорость которого находится в сильной обратной зависимости от относительной влажности воздуха и количества осадков $(31,37,38)$. В результате сложного взаимодействия между генотипом и средой наблюдается неустойчивая динамика потери влаги. Так, в условиях, не лимитирующих физиологические и физические процессы потери влаги, интенсивность влагоотдачи у конкретных образцов воспроизводится достаточно стабильно и слабо варьирует по годам $(29,31,39)$. В то же время неблагоприятный гидротермический фон может нивелировать проявление генетических особенностей гибридов (40). Избыточное увлажнение в этот период отрицательно влияет на динамику влажности зерна даже у гибридов с потенциально высокой способностью к потере влаги.

Сложность селекции кукурузы на ускоренную потерю влаги зерном состоит в том, что она часто сопряжена со снижением общей адаптивности растений к неблагоприятным факторам среды, в частности к водному стрессу (29). Вместе с тем отмечается нестабильность отрицательной корреляции уборочной влажности и урожайности зерна, что делает возможным позитивный отбор по обоим признакам и создание гибридов с быстрой влагоотдачей без снижения урожайности (37).

Для северной зоны возделывания кукурузы результативность селекции на способность к ускоренной потере влаги зерном не определена, а вероятность проявления генетического потенциала гибридов по этому признаку в условиях Урала нуждается в экспериментальной оценке на фоне типичных для региона колебаний гидротермических условий.

В нашем исследовании впервые установлено, что на юге России на фоне погодных условий, слабо лимитирующих процесс потери влаги зерном кукурузы, его уборочная влажность обусловлена скоростью влагоотдачи в предуборочный период, тогда как в Уральском регионе на периодически неблагоприятном фоне - главным образом скороспелостью изученных гибридов.

Цель работы - выявление гибридов кукурузы с повышенной скоростью потери влаги в период созревания зерна и оценка проявления этого признака на неблагоприятном гидротермическом фоне.

Методика. Исследования проводили в 2016-2018 годах в двух контрастных географических пунктах - в предгорной зоне Северного Кавказа (опытное поле Всероссийского НИИ кукурузы, п. Пятигорский, Предгорный р-н, Ставропольский край) и в северной лесостепи Южного Урала (Южно-Уральский ГАУ, с. Миасское, Красноармейский р-н, Челябинская обл.) - на шести ультраранних гибридах кукурузы (Zea mays L.) Hyp, Pocc 130 МВ, Обский 140 СВ, Кубанский 141 СВ, Машук 150 МВ, Уральский 150 и раннеспелом Биляр 160. Полевой опыт был заложен в 3-кратной повторности методом организованных повторений с рандомизированным размещением вариантов. Площадь экспериментальной делянки - 28 м $^{2}$. Сроки посева на Северном Кавказе - III декада апреля, на Южном Урале II декада мая. Фактическая густота растений при ручном формировании 70 тыс/га. Регистрировали фазы всходов, цветения початка и физиологической спелости зерна, о наступлении которой судили по появлению темного слоя у основания зерновки $(30,31)$. Влажность зерна на Северном Кавказе оценивали с 25 июля по 11 сентября, на Южном Урале - с 15 августа по 10 октября. 
Влажность зерна определяли гравиметрическим методом. Образцы массой не менее 70 г высушивали при температуре $150{ }^{\circ} \mathrm{C}$ (сушильный шкаф SNOL 58/350, «Elektrotechnika, AB», Литовская Республика) до постоянной массы (ее определяли с использованием электронных весов CAS MW-II, «CAS Corporation», Республика Корея). Для анализа отбирали и полностью обмолачивали средние образцы початков массой от 1,2 до 1,8 кг по 10 шт. в 3 повторениях. При выборе метода мы руководствовались критерием минимальной погрешности измерений. Периодический отбор проб зерна проводили с интервалом в 3-7 сут, что обеспечивало от 8 до 16 контрольных точек.

Статистические гипотезы проверяли методами дисперсионного, корреляционного и регрессионного анализов. О достоверности различий между средними по вариантам судили по критерию Фишера $(F)$ и наименьшей существенной разности (HCP, least significant difference, LSD). Скорость потери влаги зерном рассчитывали, как коэффициент линейной регрессии $\left(\mathrm{b}_{i}\right)$ влажности зерна на $i$-е даты наблюдений. Значимость коэффициентов корреляции и регрессии оценивали по величине ошибок этих параметров $\left(\mathrm{S}_{r}, \mathrm{~S}_{b}\right)$ и $t$-критерию Стьюдента. Для оценки внутригруппового варьирования значений уборочной влажности использовали стандартное отклонение (S). Уровень значимости критических значений статистических параметров $\mathrm{p}=0,05$. Для статистического анализа пользовались надстройкой «Анализ данных» табличного процессора Microsoft Excel 2016.

Результаты. В годы исследований среднемесячная температура воздуха на Северном Кавказе превышала аналогичный показатель Южного Урала в мае на 3-8 ${ }^{\circ} \mathrm{C}$, в июле и июне - на 3-7 ${ }^{\circ} \mathrm{C}$, в августе и сентябре на 5-9 ${ }^{\circ} \mathrm{C}$ (табл. 1). Месячные суммы осадков в обоих пунктах колебались в значительных пределах, но в Кавказском регионе в августе и сентябре наблюдался их минимум. Это ежегодно приводило к снижению относительной влажности воздуха к концу вегетации. На Урале наблюдалось более равномерное распределение осадков по месяцам, что при пониженной температуре вызывало устойчивое повышение влажности воздуха в период созревания зерна. Отмеченные различия обеспечили более благоприятный фон для развития растений, накопления сухого вещества в зерне и снижения его влажности в предуборочный период на Северном Кавказе.

1. Погодные условия в географических зонах проведения исследований гибридов кукурузы (Zea mays L.) на содержание влаги в зерне

\begin{tabular}{|c|c|c|c|c|c|c|}
\hline \multirow{2}{*}{ Месяц } & \multicolumn{3}{|c|}{ Северный Кавказ } & \multicolumn{3}{|c|}{ Южный Урал } \\
\hline & 2016 год & 2017 год & 2018 год & 2016 год & 2017 год & 2018 год \\
\hline \multicolumn{7}{|c|}{ Среднемесячная температура воздуха, ${ }^{\circ} \mathrm{C}$} \\
\hline Май & 17,9 & 13,8 & 17,9 & 12,0 & 10,7 & 9,8 \\
\hline Июнь & 22,3 & 18,8 & 21,6 & 16,5 & 16,2 & 14,6 \\
\hline Июль & 25,8 & 23,1 & 24,5 & 18,8 & 18,0 & 20,2 \\
\hline Август & 27,3 & 22,4 & 21,3 & 18,3 & 17,4 & 15,9 \\
\hline Сентябрь & 18,7 & 18,5 & 19,5 & 11,2 & 9,7 & 11,3 \\
\hline \multicolumn{7}{|c|}{ Месячная сумма осадков, мм } \\
\hline Май & 93 & 218 & 80 & 16 & 60 & 40 \\
\hline Июнь & 134 & 61 & 79 & 78 & 113 & 60 \\
\hline Июль & 46 & 56 & 65 & 40 & 91 & 37 \\
\hline Август & 0 & 25 & 39 & 56 & 26 & 95 \\
\hline \multirow[t]{2}{*}{ Сентябрь } & 9 & 8 & 20 & 38 & 16 & 19 \\
\hline & С ред н ем есяч & ая о тно & и тельн а я & в л а жн ость & в о з д у х а, \% & \\
\hline Май & 50,9 & 50,8 & 52,0 & 50,6 & 51,3 & 60,6 \\
\hline Июнь & 52,8 & 54,6 & 56,4 & 64,3 & 61,2 & 64,7 \\
\hline Июль & 64,1 & 62,6 & 61,0 & 69,6 & 69,0 & 73,2 \\
\hline Август & 62,7 & 59,2 & 59,4 & 72,8 & 71,2 & 83,4 \\
\hline Сентябрь & 58,8 & 57,4 & 58,8 & 73,7 & 71,9 & 74,1 \\
\hline
\end{tabular}

В Северо-Кавказском регионе полные всходы кукурузы наблю- 
дались через 8-16 сут после посева в зависимости от темпов прогревания почвы, тогда как на Южном Урале - через 21-23 сут. В 2016-2017 годах дальнейшее развитие растений до фазы цветения початка происходило на относительно благоприятном температурном фоне, поэтому продолжительность периода от всходов до этой фазы в обеих климатических зонах оказалась сопоставимой (54-58 сут). Исключение составил 2018 год, когда на фоне дефицита тепла в условиях Урала наблюдалось удлинение этого периода в среднем на 10 сут. Наибольшей продолжительностью периода от всходов до цветения початка отличался раннеспелый гибрид Биляр 160, остальные образцы развивались на 3-4 сут раньше и не показали значительных различий по динамике цветения внутри ультраранней группы. Календарные сроки цветения в северном пункте исследований наступали на 18-40 сут позднее, чем на юге страны, и приходились на III декаду июля-начало августа (табл. 2). В условиях Северного Кавказа цветение наблюдалось в третьей декаде июня - начале июля. Зерно достигало физиологической спелости в период с 1 по 7 августа, а процессы созревания и налива ультраранних гибридов проходили на фоне благоприятного сочетания температуры воздуха и увлажнения. Следовательно, погодные условия на юге страны не ограничивали скорость потери влаги зерном, что обеспечило объективную оценку различий между гибридами по исследуемому признаку.

2. Сроки цветения початка и достижения физиологической спелости у гибридов кукурузы (Zea mays L.), оцениваемых по скорости потери влаги зерном, в двух географических зонах (2016-2018 годы)

\begin{tabular}{|c|c|c|c|c|c|c|}
\hline \multirow{2}{*}{ Гибрид } & \multicolumn{3}{|c|}{ Южный Урал } & \multicolumn{3}{|c|}{ Северный Кавказ } \\
\hline & 2016 год & 2017 год & 2018 год & 2016 год & 2017 год & 2018 год \\
\hline \multicolumn{7}{|c|}{ 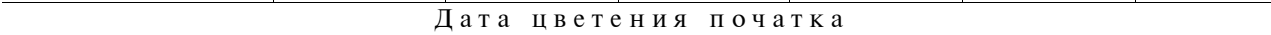 } \\
\hline Обский 140 СВ & 20.07 & 28.07 & 07.08 & 27.06 & 03.07 & 30.06 \\
\hline Кубанский 141 СВ & 20.07 & 28.07 & 07.08 & 27.06 & 03.07 & 30.06 \\
\hline Hyp & 19.07 & 27.07 & 05.08 & 26.06 & 02.07 & 28.06 \\
\hline Машук 150 МВ & 20.07 & 28.07 & 06.08 & 27.06 & 01.07 & 28.06 \\
\hline Pocc $130 \mathrm{MB}$ & 20.07 & 28.07 & 07.08 & 27.06 & 02.07 & 29.06 \\
\hline Уральский 150 & 19.07 & 27.07 & 08.08 & 27.06 & 03.07 & 31.06 \\
\hline Биляр 160 & 23.07 & 31.07 & 11.08 & 30.06 & 06.07 & 02.07 \\
\hline \multicolumn{7}{|c|}{ Дата наступления физиологической } \\
\hline Обский 140 СВ & 12.09 & 13.08 & 09.10 & 02.08 & 01.08 & 02.08 \\
\hline Кубанский 141 СВ & 12.09 & 14.08 & 09.10 & 04.08 & 02.08 & 02.08 \\
\hline Hyp & 11.09 & 13.08 & 10.10 & 04.08 & 01.08 & 02.08 \\
\hline Машук 150 МВ & 12.09 & 14.08 & 10.10 & 03.08 & 01.08 & 02.08 \\
\hline Pocc 130 MB & 11.09 & 13.08 & 10.10 & 04.08 & 02.08 & 03.08 \\
\hline Уральский 150 & 12.09 & 14.08 & 11.10 & 04.08 & 03.08 & 03.08 \\
\hline Биляр 160 & 15.09 & 17.08 & - & 07.08 & 05.08 & 06.08 \\
\hline
\end{tabular}

В селекционном процессе предпочтительны методы определения влажности, не нарушающие целостности зерновки, например с использованием контактных цифровых влагомеров (31). Не имея ограничений в объеме исследуемого материала, при выборе метода мы руководствовались критерием минимальной погрешности измерений при числе контрольный точек от 8 до 16. Методики аналогичных исследований, основанные на 2-4 точках наблюдений $(29,31)$, по нашему мнению, подменяют стохастический характер зависимости функциональным или необоснованно занижают дисперсию регрессии.

Отметим, что к моменту наступления физиологической спелости зерна в конкретных условиях вегетации достоверных различий между гибридами мы не обнаружили. По критерию Фишера колебания влажности 
зерна были статистически доказаны только по географическим пунктам, при этом наблюдалась тенденция к ее снижению на юге. Так, в условиях Южного Урала влажность зерна в 2016 году варьировала от 37,4 до 41,7 \%, в 2017 - от 39,2 до 42,0 \%, в 2018 - от 38,5 до 41,9 \%; на Северном Кавказе - соответственно от 33,9 до 36,4 \%; от 36,3 до 39,6 \% и от 33,9 до 36,8 \%.

Влияние условий среды на содержание влаги в зерне кукурузы при достижении им физиологической спелости отмечается в различных климатических зонах. Так, на засушливом фоне Канады к наступлению этой фазы влажность зерна снижается до 30 \% (31), в Центральном Черноземье России - до 35-38 \% (33, 40), в условиях Южного Урала - лишь до 40-42 \% (41). Полученные нами данные лежат в пределах этих колебаний.

По результатам дисперсионного анализа данных 2016 года в условиях Северного Кавказа было выделено 4 группы гибридов по способности к влагоотдаче (табл. 3). К первой группе отнесен единственный гибрид Биляр 160, характеризующийся максимальной динамикой потери влаги; ко второй - Уральский 150, Машук 150 МВ, Кубанский 141 СВ со средней способностью к влагоотдаче; к третьей - Росс 130 МВ и Обский 140 СВ с умеренной способностью; к четвертой - гибрид Нур, для которого была характерна минимальная скорость потери влаги.

3. Характеристика гибридов кукурузы (Zea mays L.) по скорости потери влаги зерном (\%/сут) после достижения физиологической спелости в условиях Северного Кавказа $\left(b_{i} \pm \mathrm{S}_{b}, 2016-2018\right.$ годы)

\begin{tabular}{|c|c|c|c|c|}
\hline \multirow{2}{*}{ Гибрид } & \multicolumn{3}{|c|}{ Год исследований } & \multirow{2}{*}{ В среднем } \\
\hline & 2016 год & 2017 год & 2018 год & \\
\hline Нyp & $0,58 \pm 0,03$ & $0,73 \pm 0,05$ & $0,69 \pm 0,05$ & $0,67 \pm 0,03$ \\
\hline Pocc $130 \mathrm{MB}$ & $0,64 \pm 0,06$ & $0,64 \pm 0,11$ & $0,61 \pm 0,05$ & $0,63 \pm 0,04$ \\
\hline Обский 140 СВ & $0,66 \pm 0,07$ & $0,64 \pm 0,06$ & $0,64 \pm 0,04$ & $0,65 \pm 0,04$ \\
\hline Кубанский 141 СВ & $0,71 \pm 0,09$ & $0,74 \pm 0,06$ & $0,69 \pm 0,05$ & $0,71 \pm 0,03$ \\
\hline Машук 150 МВ & $0,71 \pm 0,07$ & $0,76 \pm 0,04$ & $0,67 \pm 0,05$ & $0,71 \pm 0,03$ \\
\hline Уральский 150 & $0,70 \pm 0,09$ & $0,71 \pm 0,09$ & $0,67 \pm 0,06$ & $0,69 \pm 0,03$ \\
\hline Биляр 160 & $0,81 \pm 0,11$ & $0,81 \pm 0,05$ & $0,72 \pm 0,07$ & $0,78 \pm 0,05$ \\
\hline НСР05 (гибриды) & 0,04 & 0,07 & 0,03 & 0,04 \\
\hline НСР05 (годы) & - & - & - & $F_{\text {факт. }}<F_{05}$ \\
\hline НСР05 (взаимодействие) & - & - & - & $F_{\text {факт. }}<F_{05}$ \\
\hline
\end{tabular}

Аналогичное распределение образцов наблюдалось в 2017 и 2018 годах, за исключением того, что гибрид Нур вошел в состав второй группы, показав среднюю способность к влагоотдаче. Установлено достаточно стабильное проявление признака: для большинства гибридов различия в скорости влагоотдачи по годам были незначительны и не доказаны статисти-

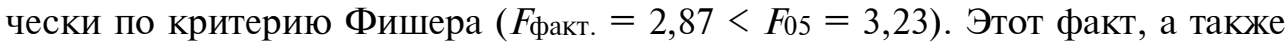
заведомо благоприятный гидротермический фон, на котором протекали заключительные процессы созревания зерна, позволяют заключить, что различия между гибридами по скорости потери влаги обусловлены в основном их генетическими особенностями и отражают результаты селекции по этому признаку. Аналогичные выводы делают L.M. Reid с соавт. (31) и X. Wang с соавт. (32). В исследованиях, проведенных в Приморском крае (26) и Северном Китае (28) с использованием среднеспелых и среднепоздних гибридов, были достигнуты значения суточной потери влаги более $1 \%$, что существенно выше максимального значения, полученного в наших исследованиях $(0,81 \%)$. С высокой вероятностью эти расхождения можно объяснить не только условиями произрастания, но и использованием гибридов различных классов созревания (34).

Принципиально иные выводы вытекают из аналогичных наблюде- 
ний, проведенных в лесостепи Челябинской области. В условиях этого региона наблюдались два этапа предуборочной динамики влажности. Как уже отмечено (37), на первом из них, продолжающемся от начала формирования зерна до физиологической спелости, скорость снижения влажности обусловлена интенсивностью накопления органического вещества в эндосперме и зависит главным образом от температуры воздуха. На втором (от физиологической до полной спелости) потеря влаги находится в обратной зависимости от относительной влажности воздуха и суммы осадков $(31,37)$. Именно на втором этапе влияние внешних условий на скорость влагоотдаче опосредовано морфологическими особенностями гибридов (29).

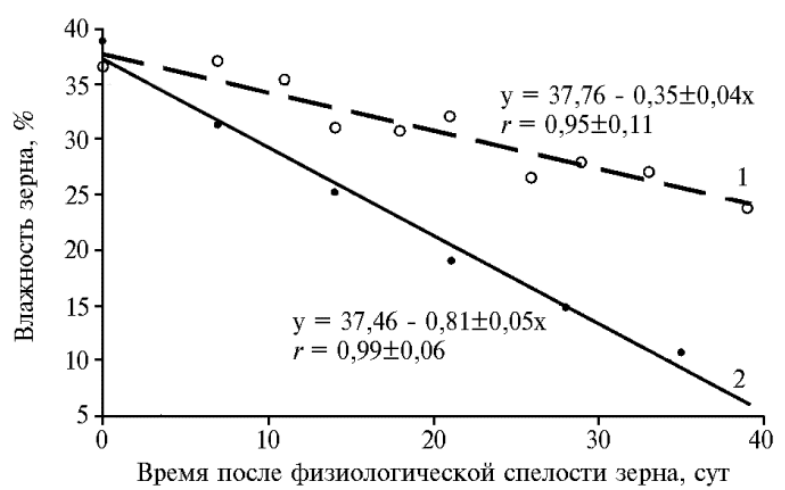

Рис. 1. Зависимость влажности зерна гибрида кукурузы (Zea mays L.) Биляр 160 от времени, прошедшего после наступления физиологической спелости, в двух географических пунктах: 1 - Южный Урал, 2 - Северный Кавказ (2016 год).

Кавказе (рис. 1). Это может быть связано не только с замедлением текущей влагоотдачи, но и с сорбцией влаги зерном под влиянием осадков (39).

4. Характеристика гибридов кукурузы (Zea mays L.) по скорости потери влаги зерном (\%/сут) после достижения физиологической спелости в условиях Южного Урала $\left(b_{i} \pm \mathrm{S}_{b}, 2016-2018\right.$ годы)

\begin{tabular}{|c|c|c|c|c|}
\hline \multirow{2}{*}{ Гибрид } & \multicolumn{3}{|c|}{ Год исследований } & \multirow{2}{*}{ В среднем } \\
\hline & 2016 год & 2017 год & 2018 год & \\
\hline Hyp & $0,23 \pm 0,02$ & $0,55 \pm 0,09$ & $0,18 \pm 0,03$ & $0,32 \pm 0,20$ \\
\hline Pocc $130 \mathrm{MB}$ & $0,23 \pm 0,02$ & $0,53 \pm 0,12$ & $0,19 \pm 0,02$ & $0,32 \pm 0,19$ \\
\hline Обский 140 СВ & $0,21 \pm 0,03$ & $0,53 \pm 0,14$ & $0,18 \pm 0,03$ & $0,31 \pm 0,19$ \\
\hline Кубанский 141 СВ & $0,22 \pm 0,02$ & $0,52 \pm 0,06$ & $0,21 \pm 0,04$ & $0,32 \pm 0,18$ \\
\hline Машук 150 МВ & $0,24 \pm 0,02$ & $0,58 \pm 0,10$ & $0,17 \pm 0,02$ & $0,33 \pm 0,21$ \\
\hline Уральский 150 & $0,24 \pm 0,03$ & $0,58 \pm 0,06$ & $0,19 \pm 0,04$ & $0,34 \pm 0,21$ \\
\hline Биляр 160 & $0,35 \pm 0,03$ & $0,72 \pm 0,07$ & Нет данных & Нет данных \\
\hline НСР05 (гибриды) & 0,06 & 0,07 & $F_{\text {факт. }}<F_{05}$ & 0,03 \\
\hline НСР05 (годы) & - & - & - & 0,02 \\
\hline НСР05 (взаимодействие) & - & - & - & $F_{\text {факт. }}<F_{05}$ \\
\hline
\end{tabular}

Иным было и распределение гибридов по скорости влагоотдачи. Методом двухфакторного дисперсионного анализа с использованием критерия Фишера доказана достоверность взаимодействия по факторам «географический пункт» и «генотип». То есть различия между гибридами по динамике влагоотдачи были обусловлены состоянием внешней среды, что косвенно подтверждается данными А. Ghete с соавт. (27). Основная особенность, выявленная для Уральского региона по данным 2016 года, заключалась в том, что по целевому признаку достоверно были выделены лишь две группы гибридов (табл. 4). Первая группа с высокой скоростью потери 
влаги $(0,35$ \%/сут), как и на Северном Кавказе, была представлена одним гибридом Биляр 160. Остальные образцы характеризовались сравнительно медленной потерей влаги (от 0,21 до 0,24 \%/сут). Такое же распределение гибридов наблюдалось и в 2017 году, несмотря на то что скорость влагоотдачи оказалась в 2-2,5 раза выше. В 2018 году вследствие значительного дефицита тепла в течение периода вегетации и позднего цветения физиологическая спелость была достигнута зерном лишь к концу периода наблюдений, что не позволило выявить каких-либо особенностей в поведении гибридов. Для гибрида Биляр 160, зерно которого в этих условиях не достигло физиологической спелости, данных по потере влаги в последний год наблюдений не получено.

Анализ научных публикаций подтверждает значительное варьирование скорости влагоотдачи зерном кукурузы в связи с морфологическими особенностями гибридов. Так, в исследованиях Z. Wang с соавт. (28), L.M. Reid с соавт. (31) и A.H. Воронина с соавт. (33) различия между селекционными образцами по этому признаку составляли 0,22-0,24 \%/сут. A. Ghete c соавт. (27) сообщают о колебаниях потери влаги инбредными линиями от 0,6 до 2,2 \%/сут. Отметим, что эти результаты были получены в традиционных зонах выращивания кукурузы на зерно (южнее $50^{\circ}$ с.ш.). Для более северных районов экспериментальных данных по рассматриваемой проблеме в научной литературе мы не обнаружили.

Результаты наших исследований позволяют заключить, что способность гибридов кукурузы к ускоренной потере влаги зерном достаточно полно проявляется на благоприятном гидротермическом фоне, тогда как на фоне избыточного увлажнения в сочетании с пониженной температурой проявление этого признака подавляется. Поэтому в северной зоне возделывания кукурузы периодически следует ожидать нивелирования уборочной влажности зерна у гибридов одной группы спелости.

Исключение могут составлять лишь некоторые генотипы, резко отличающиеся по обсуждаемому признаку. Однако и для этих образцов в условиях общего дефицита тепла генетические особенности проявляются нерегулярно. Так, в нашем исследовании способность гибрида Биляр 160 к быстрой влагоотдаче наиболее полно проявилась в виде минимального уровня влажности лишь в 2016 году (табл. 5). Два последующих года характеризовались более или менее выраженной задержкой развития всех гибридов. В этих условиях на фоне сокращенного периода от достижения физиологической спелости до конца вегетации более значимую роль играла скороспелость гибридов, что обеспечило минимальную влажность зерна у гибрида Уральский 150.

5. Уборочная влажность (\%) зерна у гибридов кукурузы (Zea mays L.) в зависимости от условий вегетации и генотипа при выращивании в двух географических зонах $(M \pm \mathrm{S}, 2016-2018$ годы)

\begin{tabular}{l|c|c|c|c|c|c}
\hline \multirow{2}{*}{\multicolumn{1}{c|}{ Гибрид }} & \multicolumn{3}{c|}{ Северный Кавказ } & \multicolumn{3}{c}{ Южный Урал } \\
\cline { 2 - 7 } & 2016 год & 2017 год & 2018 год & 2016 год & 2017 год & 2018 год \\
\hline Нур & $19,6 \pm 0,8$ & $17,9 \pm 2,4$ & $14,6 \pm 1,3$ & $26,9 \pm 0,6$ & $34,4 \pm 1,9$ & $41,3 \pm 2,6$ \\
Росс 130 МВ & $18,5 \pm 1,3$ & $16,4 \pm 2,1$ & $15,1 \pm 1,7$ & $26,9 \pm 0,7$ & $32,2 \pm 1,6$ & $41,4 \pm 3,7$ \\
Обский 140 СВ & $17,8 \pm 1,7$ & $18,2 \pm 2,6$ & $14,9 \pm 2,3$ & $25,6 \pm 1,0$ & $33,3 \pm 1,8$ & $41,7 \pm 2,1$ \\
Кубанский 141 СВ & $17,9 \pm 0,5$ & $17,1 \pm 2,0$ & $14,3 \pm 2,5$ & $25,4 \pm 0,3$ & $33,8 \pm 2,1$ & $39,8 \pm 2,2$ \\
Машук 150 МВ & $17,6 \pm 0,9$ & $17,8 \pm 3,2$ & $14,8 \pm 2,3$ & $26,3 \pm 0,5$ & $34,4 \pm 1,6$ & $41,9 \pm 3,4$ \\
Уральский 150 & $16,1 \pm 1,1$ & $16,2 \pm 2,8$ & $12,8 \pm 2,4$ & $25,2 \pm 0,9$ & $31,4 \pm 2,2$ & $38,5 \pm 2,8$ \\
Биляр 160 & $15,5 \pm 1,6$ & $17,5 \pm 1,6$ & $14,4 \pm 2,1$ & $23,7 \pm 0,9$ & $34,9 \pm 1,2$ & $43,5 \pm 4,3$ \\
НСР05 & 0,6 & $F_{\text {факт. }<F_{05}}$ & $F_{\text {факт. }<F_{05}}$ & 1,2 & 1,4 & 1,5 \\
\hline
\end{tabular}

Важное следствие, вытекающее из результатов проведенных исследо- 
ваний, заключается в принципиально разном влиянии скорости потери влаги на уборочную влажность зерна в контрастных климатических условиях. Как показал корреляционно-регрессионный анализ, тесная обратная

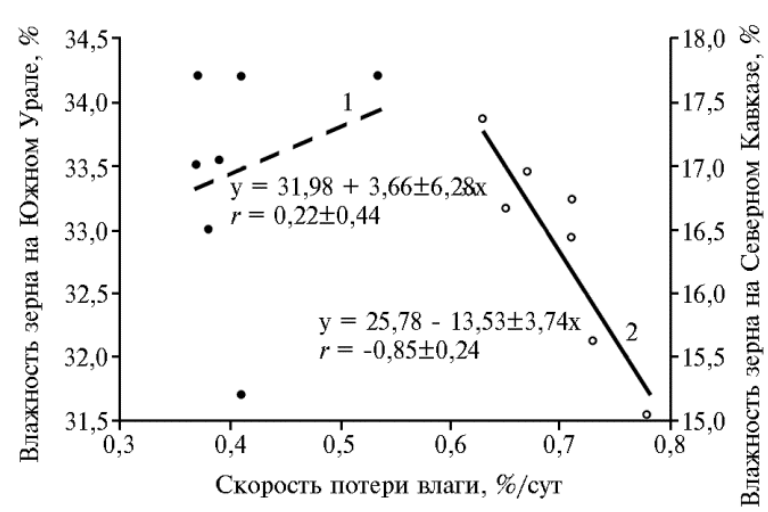

Рис. 2. Зависимость уборочной влажности зерна гибридов кукурузы (Zea mays L.) от скорости потери влаги после достижения физиологической спелости в двух географических пунктах: 1 - Южный Урал, 2 - Северный Кавказ (2016-2018 годы).

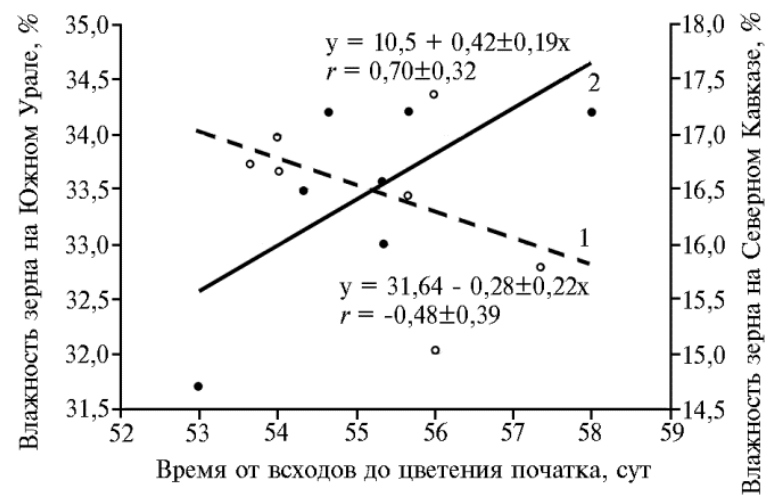

Рис. 3. Зависимость уборочной влажности зерна гибридов кукурузы (Zea mays L.) от продолжительности периода «всходы-цветение початка» в двух географических пунктах: 1 - Южный Урал, 2 - Северный Кавказ (20162018 годы).

собностью к быстрой потере влаги на заключительных этапах онтогенеза. Вклад каждого из этих признаков определяется условиями вегетации растений и созревания зерна. Для юга России, характеризующегося благоприятным гидротермическим фоном в предуборочный период, влажность зерна в значительной степени обусловлена генетической способностью гибрида к ускоренной влагоотдаче. В этих условиях скорость потери влаги зерном после достижения физиологической спелости колеблется по гибридам в среднем от 0,63 до 0,78 \%/сут. Напротив, на Урале при высокой относительной влажности и низкой температуре воздуха в предуборочный период основное значение имеет раннее цветение початка. Скорость влагоотдачи на этом фоне снижается до 0,21-0,35 \%/сут при неблагоприятных гидротермических условиях и до 0,52-0,72 \%/сут - при благоприятных, а различия между гибридами проявляются нерегулярно и зачастую нивелируются влиянием среды. Следовательно, для северной зоны кукурузосеяния селекция кукурузы на способность к быстрой потере влаги зерном имеет смысл лишь в 
сочетании с отбором на короткий вегетационный период, который должен рассматриваться как приоритетный признак при создании адаптированных гибридов. По результатам наших исследованиях для выращивания на Южном Урале может быть рекомендован ультраранний гибрид Уральский 150, который характеризуется ранним цветением в сочетании с умеренной потерей влаги зерном в предуборочный период. Высокая способность к влагоотдаче, установленная для раннеспелого гибрида Биляр 160 в условиях Северного Кавказа, не обеспечивает стабильно низкой уборочной влажности зерна в Уральском регионе.

1ФГБНУ Всероссийский НИИ кукурузы, 357528 Россия, г. Пятигорск, ул. Ермолова, 146, Поступила в редакцию e-mail: 976067@mail.ru, gorba4ewa.a@yandex.ru, vetira2014@yandex.ru; 22 сентября 2020 года

\title{
2ФГБОУ ВО Южно-Уральский ГАУ,
}

457100 Россия, Челябинская обл., г. Троицк, ул. Гагарина, 13,

e-mail: al_panfilov@mail.ru $₫$, kni1711@yandex.ru

\section{GENOTYPE AND ENVIRONMENT INFLUENCE ON THE RATE OF GRAIN MOISTURE LOSS IN CORN DURING RIPENING PERIOD}

\author{
V.S. Sotchenko ${ }^{1}$, A.E. Panfilov ${ }^{凶}$, A.G. Gorbacheva ${ }^{1}$, N.I. Kazakova ${ }^{2}$, I.A. Vetoshkina ${ }^{1}$
}

${ }^{1}$ All-Russian Research Institute of Corn, 14-B, ul. Ermolova str., Pyatigorsk, 357528 Russia, e-mail 976067@mail.ru, gorba4ewa.a@yandex.ru, vetira2014@yandex.ru;

${ }^{2}$ South Ural State Agrarian University, 13, ul. Gagarina, Troitsk, Chelyabinsk Province, 457100 Russia, e-mail al_panfilov@mail.ru ( $₫$ corresponding author), kni1711@yandex.ru

ORCID:

Sotchenko V.S. orcid.org/0000-0002-0741-4412

Panfilov A.E. orcid.org/0000-0001-5026-1274

Gorbacheva A.G. orcid.org/0000-0001-9936-4565

The authors declare no conflict of interests

Received September 22, 2020

Kazakova N.I. orcid.org/0000-0001-7623-4178

Vetoshkina I.A. orcid.org/0000-0002-8040-7040

doi: 10.15389/agrobiology.2021.1.54eng

\section{Abstract}

High grain moisture during harvesting is a factor that restrains the expansion of corn (Zea mays L.) crops in the Ural region. A decrease in the harvesting moisture content of seeds is achieved by corn breeding for early maturity (early flowering of the ear) and for accelerated moisture loss from grain in the pre-harvesting period. In our study, it was found for the first time that in the conditions of southern Russia under weather conditions that weakly limit moisture losses, the harvesting moisture of corn grain is determined by the rate of pre-harvesting moisture losses while in the Ural region where the weather conditions are periodically unfavorable the moisture losses are mainly due to the early maturity of the studied hybrids. This work aims to identify corn hybrids with an increased rate of moisture loss during grain ripening and to assess this trait under unfavorable hydrothermal conditions. The studies were carried out in 2016-2018 in two contrasting geographical sites, in the foothill zone of the North Caucasus (experimental field of the All-Russian Research Institute of Corn, the settlement Pyatigorskiy, Predgornii District of the Stavropol Territory) and in the northern forest-steppe of the Southern Urals (South Ural GAU, village Miasskoye, Krasnoarmeyskiy District, the Chelyabinsk Province). Six ultra-early corn hybrids (Zea mays L.) Nur, Ross 130 MV, Obsky 140 SV, Kubansky 141 SV, Mashuk $150 \mathrm{MV}$, Uralskiy 150 and early ripening Bilyar 160 hybrid were involved in the study. The field experiment was arranged in triplicate using a randomized field plot layout $\left(28 \mathrm{~m}^{2}\right.$ plots with a full set of hybrids per plot). The recorded phenological phases were germination, ear flowering and physiological ripeness of grain detected by the corn kernel "black layer" as an indicator of physiological maturity. The corn grain moisture was measured gravimetrically from July 25 to September 11 in the North Caucasus and from August 15 to October 10 in the South Urals. Samples weighting not less than $70 \mathrm{~g}$ were dried at $150^{\circ} \mathrm{C}$ to a constant weight (a SNOL 58/350 exicator, Elektrotechnika, AB, Republic of Lithuania; a CAS MW-II electronic Weighing Scale, CAS Corporation, Republic of Korea). For analysis, 10 ears of 1.2 to $1.8 \mathrm{~kg}$ were collected and completely threshed in three reps. Grain sampling was carried out with a 3-7-day intervals providing 8 to 16 control points. Statistical hypotheses were tested by methods of variance, correlation and regression analysis. It was found that in the northern site, the calendar dates of flowering of the ear occurred in the beginning or end of the third decade of July, that is, 22-36 days later than in the south site. In the conditions of the North Caucasus, flowering occurred in the third decade of June-early July, the grain physiological ripeness was reached from 1 to 7 August, that is, grain maturation and filling in ultra-early maturing hybrids occurred under 
favorable hydrothermal conditions. Consequently, environmental conditions did not limit the rate of moisture loss in grain, which provided reliable estimates of the differences between hybrids according to the trait. The research revealed significant differences in the rate of moisture loss both between the study sites and the hybrids. In the North Caucasian region, the rate of moisture loss in grain after reaching physiological ripeness varied for hybrids from 0.63 to $0.78 \%$ per day with slight variation over the years. Under higher relative humidity and low air temperature the likelihood of which in the pre-harvest period is high for the Ural region, the rate of moisture loss decreased to $0.21-0.35 \%$ per day, and under favorable hydrothermal conditions it reached only $0.52-0.72 \%$ per day. It has been established that the harvest moisture content of corn grain is associated with two main characteristics of hybrids, i.e., the early maturity and the ability to quickly lose moisture at the final stages of ontogenesis. The contribution of each factor is due to the conditions of grain ripening. I.e., for the south of Russia, grain moisture is largely due to the ability of a hybrid to accelerate moisture losses. On the contrary, in the conditions of the Southern Urals, the early flowering of the ear is of primary importance. Differences between hybrids in the rate of moisture loss under these conditions appear irregularly and are often leveled by the influence of the environment. Therefore, for the northern zone of corn sowing, the corn breeding for its ability to rapidly lose moisture from grain makes sense only in combination with breeding for a short growing season which should be considered as a priority trait when creating adapted hybrids.

Keywords: corn, hybrids, ultra-early maturity, ontogenesis, vegetation period, grain moisture, moisture loss rate, Southern Urals, Northern Caucasus.

\section{REFEREN CES}

1. Pahl H. Maisanbau 98. Top-Sorten bringen Bares. DLZ-Agrarmagazin, 1997, 12: 21-22.

2. Vančetović J., Ignjatović-Micić D., Božinović S., Babić M., Filipović M., Grčić N., Andjelković V. Grain quality of drought tolerant accessions within the MRI Zemun Polje maize germplasm collection. Spanish Journal of Agricultural Research, 2014, 12(1): 186-194 (doi: 10.5424/sjar/20141214392).

3. Berardo N., Mazzinelli G., Valoti P., Lagana P., Redaelli R. Characterization of maize germplasm for the chemical composition of the grain. Journal of Agricultural and Food Chemistry, 2009, 57(6): 2378-2384 (doi: 10.1021/jf803688t).

4. Pinto A.T.B., Pereira J., de Oliveira T.R., Prestes R.A., Mattielo R.R., Demiate I.M. Characterization of corn landraces planted Grown in the campos gerais region (Paraná, Brazil) for industrial utilization. Brazilian Archives of Biology and Technology, 2009, 52(Special issue): 17-28 (doi: 10.1590/S1516-89132009000700003).

5. Clark D., Dudley J.W., Tocheford T.R., LeDeaux J.R. Genetic analysis of corn kernel chemical composition in the random mated 10 generation of the cross of generations 70 of IHO $\times$ ILO. Crop Science, 2006, 46(2): 807-819 (doi: 10.2135/cropsci2005.06-0153).

6. Panfilov A.E. Nivy Zaural'ya, 2015, 11(133): 58-60 (in Russ.).

7. Zezin N.N., Namyatov M.A., Laptev V.R. Kormoproizvodstvo, 2015, 11: 25-28 (in Russ.).

8. Sotchenko Yu.V., Sotchenko E.F., Shaitanov O.L., Khusnullin M.I. Dostizheniya nauki i tekhniki $A P K, 2016,30:$ 49-53 (in Russ.).

9. Jumbo M.B., Carena M.J. Combining ability, maternal, and reciprocal effects of elite earlymaturing maize population hybrids. Euphytica, 2008, 162(2): 325-333 (doi: 10.1007/s10681-0079618-9).

10. Hyrkas A., Carena M.J. Response to long-term selection in early maturing maize synthetic varieties. Euphytica, 2005, 143(1): 43-49 (doi: 10.1007/s10681-005-2238-3).

11. Hallauer A.L., Carena M.J. Recurrent selection methods to improve germ-plasm in maize. Maydica, 2012, 57(4): 266-283.

12. Carena M.J. Maize commercial hybrids compared to improved population hybrids for grain yield and agronomic performance. Euphytica, 2005, 141(2): 201-208 (doi: 10.1007/s10681005-7072-0).

13. Ma D., Xie R., Zhang F., Li J., Li S., Long H., Liu Y., Guo Y., Li S. Genetic contribution to maize yield gain among different locations in China. Maydica, 2015, 60(1): 1-8.

14. Duvick D.N. The contribution of breeding to yield advances in maize (Zea mays L.). Advances in Agronomy, 2005, 86: 83-145 (doi: 10.1016/S0065-2113(05)86002-X).

15. Dolatabad S.S., Choukan R., Hervan E.M., Dehghani H. Multienvironment analysis of traits relation and hybrids comparison of maize based on the genotype by trait biplot. American Journal of Agricultural and Biological Science, 2010, 5(1): 107-113 (doi: 10.3844/ajabssp.2010.107.113).

16. Meseka S.K., Menkir A., Ajala S. Genetic analysis of performance of maize inbred lines under drought stress. Journal of Crop Improvement, 2011, 25(5): 521-539 (doi: 10.1080/15427528.2011.592570).

17. Liakat Ali M., Luetchens J., Singh A., Shaver T.M., Kruger G.R., Lorenz A.J. Screening genetic variation in maize for deep root mass in greenhouse and its association with grain yield under water-stressed field conditions. Maydica, 2015, 60(1): 1-13.

18. Babić V., VančetovićJ., ProdanovićS., Kravić N., Babić M., AndelkovićV. Numerical classification 
of western balkan maize drought tolerant landraces. Journal of Agricultural Science and Technology, 2015, 17(2): 455-468.

19. Camus-Kulandaivelu L., Veyrieras J.B., Madur D., Combes V., Fourmann M., Barraud S., Dubreuil P., Gouesnard B., Manicacci D., Charcosset A. Maize adaptation to temperate climate: Relationship between population structure and polymorphism in the Dwarf8 gene. Genetics, 2006, 172(4): 2449-2463 (doi: 10.1534/genetics.105.048603).

20. Hoecker N., Keller B., Piepho H.P., Hochholdinger F. Manifestation of heterosis during early maize (Zea mays L.) root development. Theoretical and Applied Genetics, 2006, 112: 421-429 (doi: 10.1007/s00122-005-0139-4).

21. Suprunov A.I., Lavrenchuk N.F. Trudy Kubanskogo gosudarstvennogo agrarnogo universiteta, 2006, 3: 122-129 (in Russ.).

22. Sezegen B., Carena M.J. Divergent recurrent selection for cold tolerance in two improved maize populations. Euphytica, 2009, 167(2): 237-244 (doi: 10.1007/s10681-008-9875-2).

23. Okumus A. Genetic variation and relationship between Turkish flint Maize landraces by RAPD markers. American Journal of Agricultural and Biological Science, 2007, 2(2): 49-53.

24. Panfilov A.E., Ovchinnikov P.Yu. Kormoproizvodstvo, 2019, 10: 26-30 (in Russ.).

25. Panfilov A.E., Kazakova N.I. APK Rossii, 2018, 25(5): 586-591 (in Russ.).

26. Bozhko O.V. Agrarnaya Rossiya, 2018, 3: 3-6 (doi: 10.30906/1999-5636-2018-3-3-6) (in Russ.).

27. Gheţe A., Copândean A., Haş I., Haş V., Duda M., Tinca E., Călugăr R., Varga A., Moldovan C. Moisture loss dynamics in some inbred lines, parental forms of maize hybrids, created at ARDS Turda. Research Journal of Agricultural Science, 2016, 48(1): 51-56.

28. Wang Z., Wang X., Zhang L., Lui X., Di H., Li T., Jin X. QTL underlying field grain drying rate after physiological maturity in maize (Zea mays L). Euphytica, 2012, 185(3): 521-528 (doi: 10.1007/s10681-012-0676-2).

29. Sala R.G., Andrade F.H., Camadro E.L., Cerono J.C. Quantitative trait loci for grain moisture at harvest and field grain drying rate in maize (Zea mays L.). Theoretical and Applied Genetics, 2006, 112: 462-471 (doi: 10.1007/s00122-005-0146-5).

30. Maiorano A., Mancini M. Water relationships and temperature interactions in maize grain during maturation. Field Crops Research, 2010, 119(2-3): 304-307 (doi: 10.1016/j.fcr.2010.07.019).

31. Reid L.M., Morrison M.J., Zhu X., Wu J., Woldemariam T., Voloaca C., Xiang K. Selecting maize for rapid kernel drydown: timing of moisture measurement. Maydica, 2014, 59(1): 9-15.

32. Wang X., Ren X., Mei N., Xie Y., Yang X., Zhao R. Genome-wide association analysis for the genetic basis of seven traits associated with corn grain moisture and ear threshing rate. International Journal of Agriculture and Biology, 2019, 21(4): 810-818 (doi: 10.17957/IJAB/15.0961).

33. Voronin A.N., Khoroshilov S.A., Zhurba G.M., Netsvetaev V.P. Kukuruza i sorgo, 2006, 3: 2-5 (in Russ.).

34. Tereshchenko A.A., Suprunov A.I. Dostizheniya nauki i tekhniki APK, 2016, 30(1): 30-32 (in Russ.).

35. Yang J., Carena M.J., Uphaus J. Area under the curve (AUDDC): a method to evaluate rate of dry down in maize. Crop Science, 2010, 50(6): 2347-2354 (doi: 10.2135/cropsci2010.02.0098).

36. Sweeney P.M., Martin S.K.St., Clucas C.P. Indirect inbred selection to reduce grain moisture in maize hybrids. Crop Science, 1994, 34(2): 391-396 (doi: 10.2135/cropsci1994.0011183X003400020016x).

37. Li L., Wang K., Xie R., Ming B., Zhao L., Li S., Hou P. Corn kernel weight and moisture content after physiological maturity in field. Scientia Agricultura Sinica, 2017, 50(11): 2052-2060 (doi: 10.3864/j.issn.0578-1752.2017.11.011).

38. Wang X., Ma T., Yang T., Song P., Chen Z., Xie H. Monitoring model for predicting maize grain moisture at the filling stage using NIRS and a small sample size. International Journal of Agricultural and Biological Engineering, 2019, 12(2): 132-140 (doi: 10.25165/j.ijabe.20191202.4708).

39. Volenik M., Rozman V., Kalinovic I., Liška A., Darko K., Branimir Š. Influence of relative humidity and temperature on the changes in grain moisture in stored soybean and maize. Agriculturae Conspectus Scientificus, 2007, 72(3): 215-219.

40. Orlyanskii N.A. Kukuruza i sorgo, 2007, 6: 2-3 (in Russ.).

41. Ivanova E.S., Zamyatin A.D. APK Rossii, 2016, 23(3): 659-663 (in Russ.). 